\title{
Efficacy of 165 rRNA variable regions high- resolution melt analysis for bacterial pathogens identification in periprosthetic joint infections
}

\author{
Samaneh Bourbour ${ }^{1}$, Mohammad Emaneini ${ }^{1}$, Mahmoud Jabalameli ${ }^{2}$, Seyed Mohammad Javad Mortazavi ${ }^{3}$, \\ Mohamad Naghi Tahmasebi ${ }^{3}$, Amirheckmat Taghizadeh ${ }^{4}$, Arash Sharafatvaziri ${ }^{3}$, Reza Beigverdi ${ }^{1}$ and

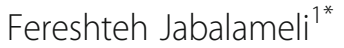

\begin{abstract}
Background: Accurate and rapid identification of microorganisms causing periprosthetic joint infections (PJIs) are necessary for choosing an appropriate antibiotic therapy. Therefore, molecular techniques are suggested for diagnosis in suspected PJls. The Broad-range PCR and High-Resolution Melt Analysis (HRMA) were evaluated for the identification of causative organisms of PJls in this study.

Results: For 47 of 63 specimens, both the culture and broad-range PCR were positive. The culture was found to be able of organism's detection in $74.6 \%$ (47/63) of patients. Of 47 positive cultures, 11 (23.4\%) were polymicrobial and 36 (76.59\%) were monomicrobial cultures, in which 34 (91.89\%) cases were detected by HRM assay. The sensitivity, specificity of HRMA vs monomicrobial culture were $91.89,93.75 \%$, respectively. The sensitivity, specificity of total HRMA (mono + poly) vs culture were $82.92,93.75 \%$.
\end{abstract}

Conclusions: HRM assay coupled with broad-range PCR are effective screening, rapid, and relatively cost-effective methods for discrimination of PJls especially in aiding culture method. Using computer programs such as the Matlab-2018b program for HRM data analysis is also valuable and helpful in diagnosis.

Keywords: Periprosthetic joint infections, Pathogens, Broad-range PCR, High-resolution melt analysis

\section{Background}

Periprosthetic joint infections (PJIs), are among important threats to global public health and are considered as a main challenge after elective surgical procedures $[1,2]$. Arthroplasty is a frequent surgical procedure for joint replacement in end-stage arthritis $[3,4]$. One of the most serious and devastating complications after joint

\footnotetext{
* Correspondence: jabalamf@tums.ac.ir

'Department of Microbiology, School of Medicine, Tehran University of Medical Sciences, Tehran, Iran

Full list of author information is available at the end of the article
}

arthroplasty is PJI $[5,6]$. Also, higher revision arthroplasty rates could be due to PJI [7].

Prevalence of PJI is steadily increasing, mostly due to more frequent usage of prosthetic joints [1,2]. Given the projected increase of joint replacement over the coming decades turned into a challenging issue, such as diagnosis challenges, high morbidity, the economic burden for patients and healthcare costs $[5,8,9]$. In managing PJI, one of the most important aspects is a prompt and definitive diagnosis of the causative organisms for the selection of appropriate treatment options and avoiding unnecessary multiple surgical procedures. In up to $50 \%$

(c) The Author(s). 2021 Open Access This article is licensed under a Creative Commons Attribution 4.0 International License, which permits use, sharing, adaptation, distribution and reproduction in any medium or format, as long as you give appropriate credit to the original author(s) and the source, provide a link to the Creative Commons licence, and indicate if changes were made. The images or other third party material in this article are included in the article's Creative Commons licence, unless indicated otherwise in a credit line to the material. If material is not included in the article's Creative Commons licence and your intended use is not permitted by statutory regulation or exceeds the permitted use, you will need to obtain permission directly from the copyright holder. To view a copy of this licence, visit http://creativecommons.org/licenses/by/4.0/ The Creative Commons Public Domain Dedication waiver (http://creativecommons.org/publicdomain/zero/1.0/) applies to the data made available in this article, unless otherwise stated in a credit line to the data. 
of PJI cases, the infecting organism is not isolated in cultures and the risk of reinfection in negative culture cases is 4.5 times higher than in positive culture cases [10-12].

Since most of the methods for the detection of causative bacteria are time-consuming and costly, several fast and accurate molecular techniques have been investigated to improve the sensitivity of PJI diagnosis [13]. Therefore, molecular techniques such as broad-range PCR targeting the 16SrRNA gene (broad-range PCR) and high-resolution melt curve analysis (HRMA) of $16 \mathrm{~s}$ hypervariable gene regions contribute to PJIs rapid diagnosis. The Full-length $16 S$ rRNA gene presents in all bacteria and is including nine hypervariable regions (V1V9). Broad-range PCR identify non-viable bacterial DNA in specimens whose culture are negative because of consuming antibiotics $[14,15]$.

The HRMA is as post-PCR technique with amplified on PCR amplicons and there is a relation between temperature and extent of double-stranded DNA denaturation. In this technique, \%G-C content, amplicons length $(<300 \mathrm{bp})$ and the nucleotide sequence contribute to melting temperature (Tm) and fluorescent dye binding to double-stranded DNA in the PCR reaction. In this method, as the temperature increases, the doublestranded DNA detaches into single-strands and leading to a reduction in fluorescence intensity. The advantages of this approach can be mentioned to rapid-speed, relatively cost-effective, use of generic instrumentation accessible in many laboratories, simplicity, single step, and an alternative to gel-based techniques [16-19].

An 18-month study was performed on patients with knee and hip PJIs from tertiary care hospitals. In this research, the infecting organisms were identified using cultures and phenotypic methods, broad-range PCR, HRMA in synovial fluid and tissue specimens from patients with suspected knee and hip PJIs. The raw data of HRMA were translated and analyzed by the Matlab$2018 \mathrm{~b}$ program. To our knowledge, there have been no studies evaluating $16 S$ rRNA gene variable regions HRMA to identify the causative organisms in PJIs.

\section{Results}

Over the study period, 63 patients (42 women and 21 men) with suspected knee or hip PJIs, and criteria included, were analyzed. Of 63 patients undergoing total arthroplasty, 33 knee and 30 hip were involved.

The specimens consisted of 39 synovial fluids and 24 tissues. Among the total 63 patients who were investigated, $47(74.6 \%)$ had positive culture, while in 16 $(25.38 \%)$ the cultures were negative. Of 47 positive cultures, the most common causative pathogen was Staphylococcus aureus (S. aureus, 17 cases, 36.17\%) followed by coagulase-negative staphylococci (CoNS, 14 cases, 29.78\%). Methicillin-resistant S. aureus (MRSA) was isolated in 5 cases (10.63\%) and methicillin-resistant coagulase-negative staphylococci (MR-CoNS) were isolated in seven cases (14.89\%). No strains were found vancomycin-resistance among Methicillin-resistant Staphylococcus spp. (MRS spp) isolates by E-test.

Of 47 positive cultures, $36(76.59 \%)$ infections were monomicrobial and $11(23.4 \%)$ were polymicrobial. In monomicrobial PJIs, the most common isolated bacterium was $S$. aureus $(12 / 47,25.53 \%)$ and several Gram-negative bacterial strains were isolated from specimens, such as Escherichia coli, Klebsiella pneumonia, Pseudomonas aeruginosa. Also, two isolates of Brucella melitensis were detected from monomicrobial PJIs. Enterococcus faecalis $(11 / 47,23.4 \%)$ isolates were the most commonly identified species in polymicrobial PJIs which one isolate was vancomycin-resistant enterococci (VRE). Escherichia coli (6/47, 12.76\%) isolates were the most frequent isolate of Gram-negative in polymicrobial PJIs. Anaerobic pathogens as Finegoldia magna (F. magna) and Cutibacterium avidum ( $C$. avidum) were isolated in three cases (5.45\%) in mono and polymicrobial PJIs which are shown in Fig. 1. Broad-range PCR was performed on 63 specimens of which 47 specimens were positive. Overall, the results of culture and broad-range PCR were not in agreement with the two cases. There was one case of positive broad-range PCR in which the culture was negative and F. magna was detected with sequencing method. Furthermore, there was one case of culturepositive and $S$. aureus was identified in which broadrange PCR did not detect the organism.

At first, a reference library based on Tm and melting curves of 19 reference strains was established by HRMA for detection of pathogens. Derivative and Aligned Melt Curves of three strains (Klebsiella pneumonia ATCC 700603, S. aureus ATCC 25923 and Brucella melitensis) with three 16SrRNA regions are outlined in Fig. 2. The generated melt curves of samples (48 synovial fluid and tissue specimens) were compared with melt curve database of reference strains to perform bacterial identification that are shown in Fig. 3. The causative organisms were identified by HRMA in all 47 cases which broad-range PCR were positive (36 monomicrobial and 11 polymicrobial infections). Among 37 detected monomicrobial infections by HRMA, 34 (91.89\%) cases were concordant with culture in which the four cases were accordant at the genus level and three (8.1\%) cases were discordant with culture. The sensitivity, specificity, accuracy, Positive predictive values (PPV) and Negative predictive (NPV) of HRMA vs culture for detecting the monomicrobial infections in PJI samples were 91.89, 93.75, 97.14, 83.33, and 92.45\%, respectively.

From 11 remaining case with a polymicrobial positive culture, HRMA was able to detect 7 cases (63.63\%) at 


\section{Isolated microorganisms from periprosthetic joint infections}

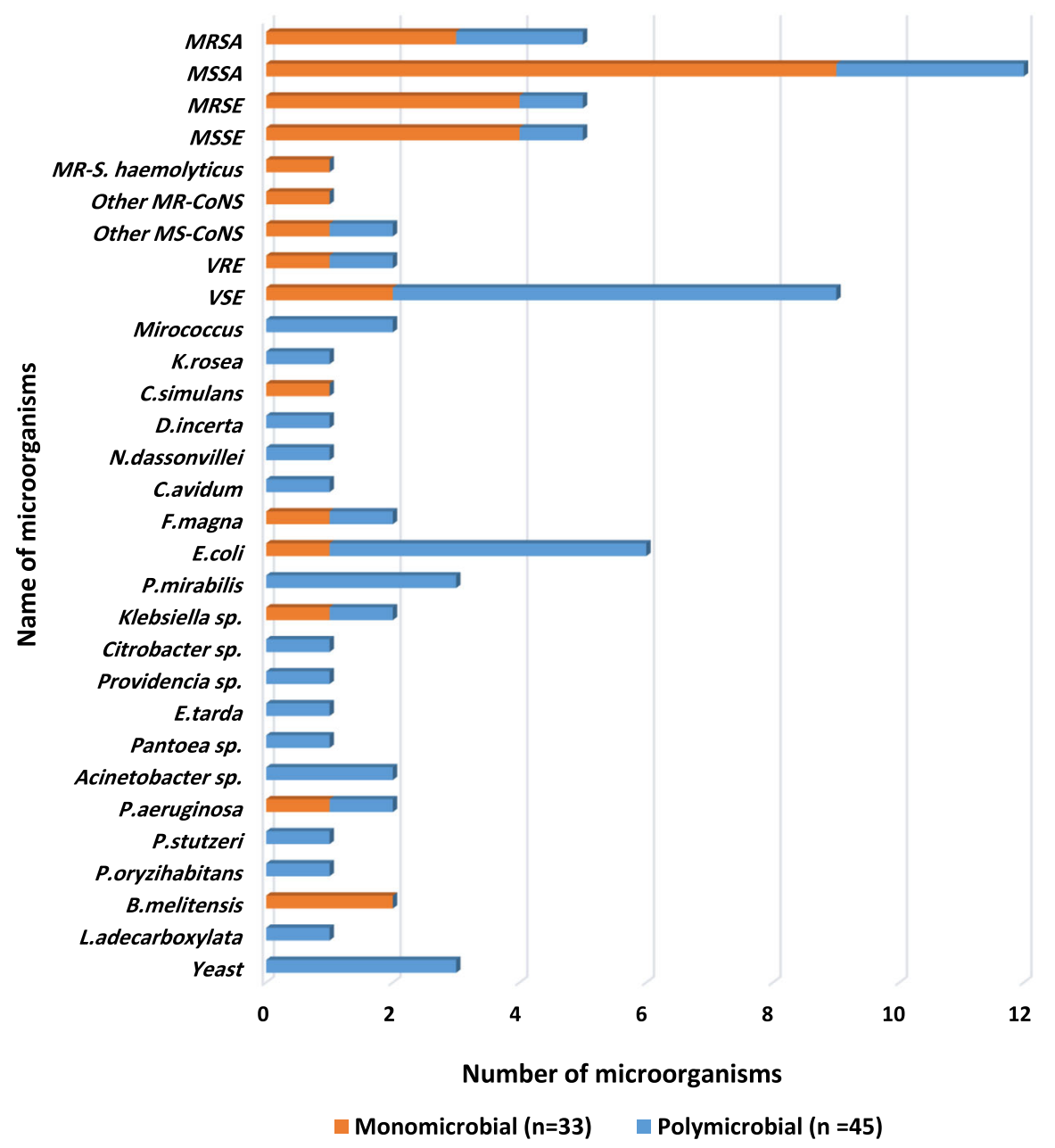

Fig. 1 Distribution of detected microorganisms from PJIs MRSA: Methicillin-resistant Staphylococcus aureus, MSSA: Methicillin-susceptible Staphylococcus aureus, MRSE: Methicillin-resistant Staphylococcus epidermidis, MSSE: Methicillin-susceptible Staphylococcus epidermidis, MR-S. haemolyticus: Methicillin-resistant Staphylococcus haemolyticus, Other MR-CoNS: Other Methicillin-Resistant Coagulase-Negative Staphylococci, Other MS-CoNS: Other Methicillin-susceptible Coagulase-Negative Staphylococci, VSE: Vancomycin-sensitive Enterococcus faecalis, VRE: Vancomycin-resistant Enterococcus faecalis, C.simulans: Corynebacterium simulans, D.incerta: Desemzia incerta, N.dassonville: Nocardiopsis dassonville, C.avidum: Cutibacterium avidum, F.magna: Finegoldia magna, B.melitensis: Brucella melitensis, E.coli: Escherichia coli, P.mirabilis: Proteus mirabilis, E.tarda: Edwardsiella tarda, P.aeruginosa: Pseudomonas aeruginosa, P.stutzeri: Pseudomonas stutzeri, P.oryzihabitans: Pseudomonas oryzihabitans, L.adecarboxylata: Leclercia adecarboxylata

least with one of the causative bacterial species (one case was identified at the genus level) that were concordance to culture findings (Table 1). The Overall sensitivity, specificity, PPV and NPV, and accuracy of total HRMA (mono + poly) vs culture were 82.92, 93.75, 97.14, 68.18, and $85.96 \%$, respectively.

All three gene regions of the reference strains of $S$. aureus and S. epidermidis outlined in Fig. 4, indicating that the two strains are distinct.

Finally, for confirmation of culture and HRMA detected strains, the sequencing method was performed.
GenBank accession numbers for the $16 S$ rRNA sequencing of clinical isolates determined in the present study are; Finegoldia magna MH201143.1, Finegoldia magna MK516859.1, Staphylococcus epidermidis MK516263.1, Enterococcus faecalis MK516261.1, Corynebacterium simulans MK516260.1, Cutibacterium avidum MH201146.1.

\section{Discussion}

There are significant challenges in management of PJIs. For effective management, accurate microbiologic 


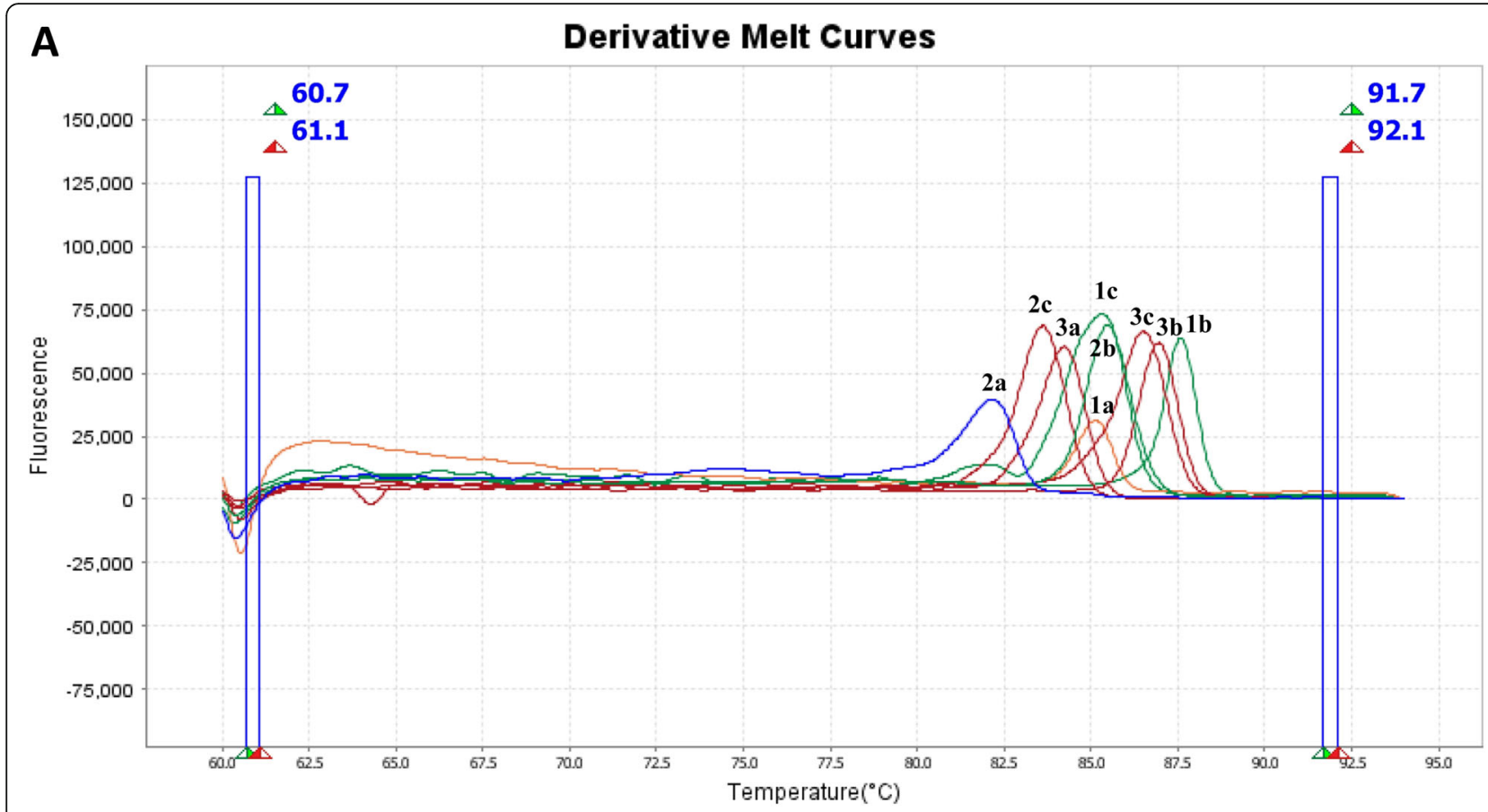

B

Aligned Melt Curves

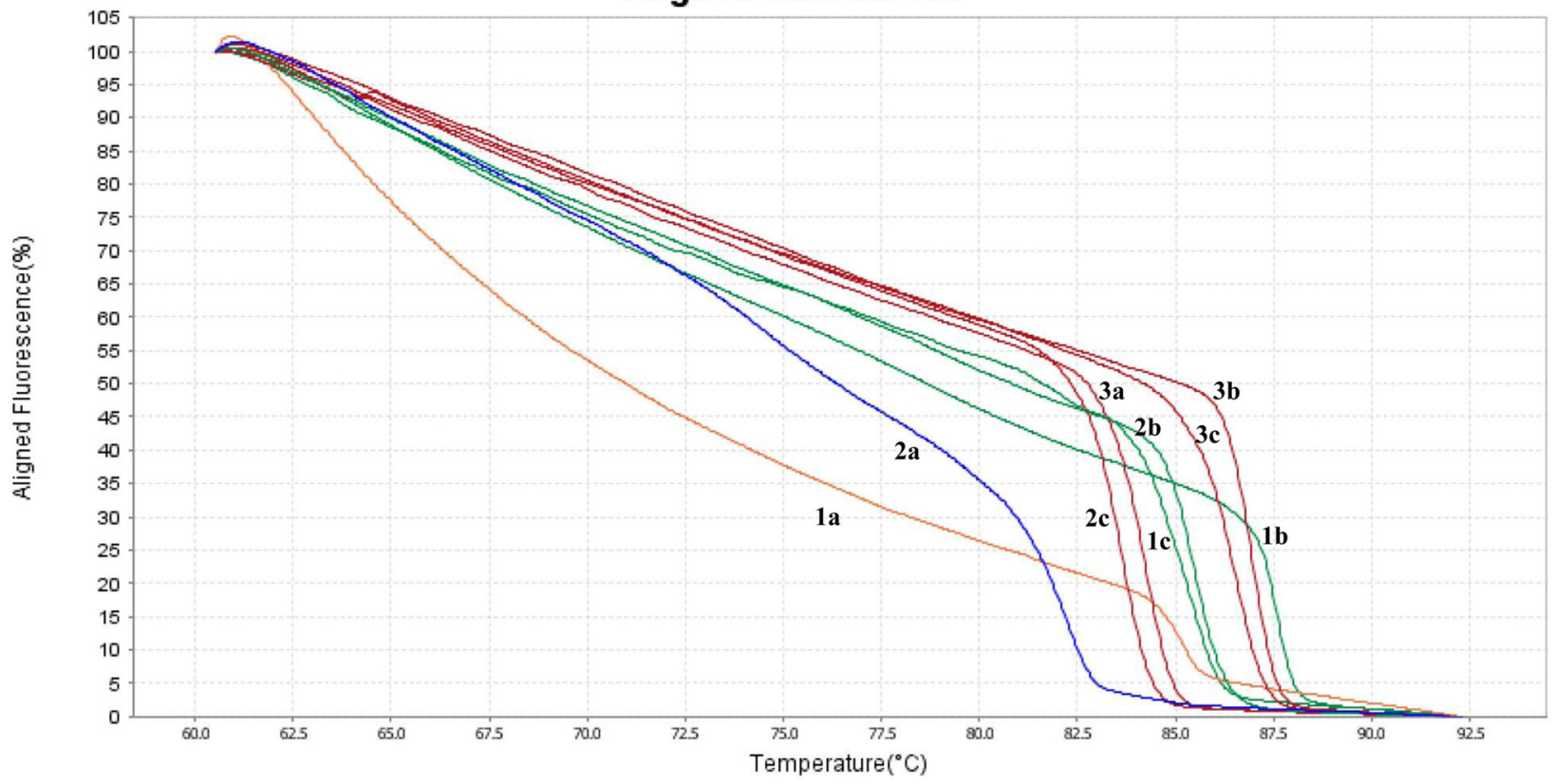

Fig. 2 A: HRMA Derivative Melting Curves and B: HRMA Aligned Melting Curves for some of Reference strains 1a: V1 region of K. pneumonia ATCC 700603, 1b: V3 region of K. pneumonia ATCC 700603, 1c: V6 region of K. pneumonia ATCC 700603, 2a: V1 region of S. aureus ATCC 25923, 2b: V3 region of S. aureus ATCC 25923, 2c: V6 region of S. aureus ATCC 25923, 3a: V1 region of B. melitensis 16 M ATCC 23456, 3b: V3 region of B. melitensis 16 M ATCC 23456, 3c: V6 region of B. melitensis 16 M ATCC 23456

diagnosis of infecting organisms is important. Falsenegative culture and longtime for diagnosis are critical challenges for conventional methods. Molecular methods had been suggested solving these problems but their usage in routine diagnostics is still controversial.
In the present study, the prevalence of infectioncausing microorganisms was determined and the role of molecular methods such as broad-range PCR and HRMA in assisting the culture method for the identification of microorganisms was investigated. 


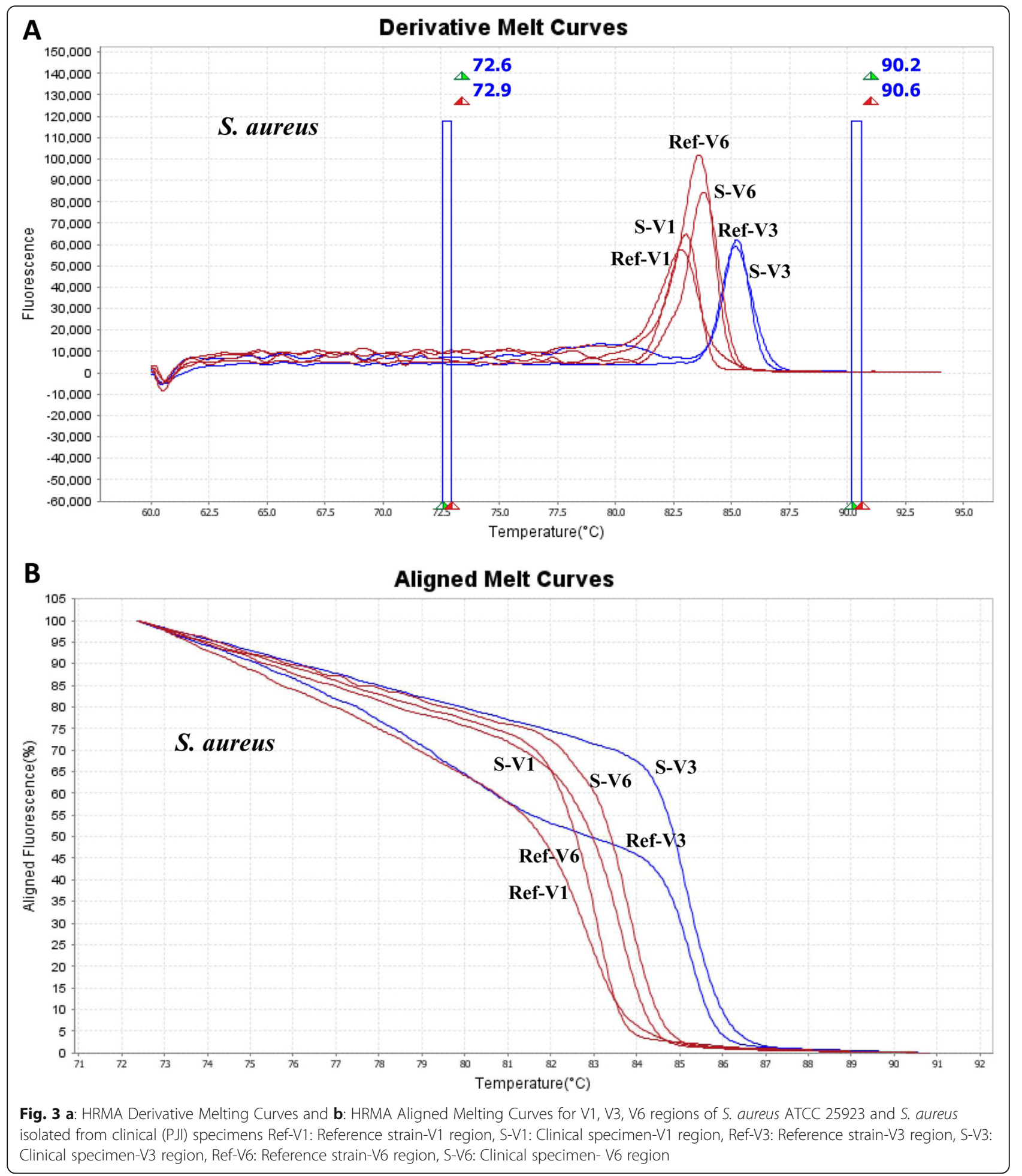

The main advantages of HRMA are the implementation of a relatively cost-effective, single-step and rapid technique for directly extracted clinical specimens and compared to other molecular methods.

The culture method was found to be able of detection of microorganisms in $74.6 \%(47 / 63)$ of patients as determined by the Philadelphia Consensus Criteria (PCC) and clinician's diagnosis. This improvement can easily be explained by optimal conditions such as accurate sampling, use of various and appropriate culture media in different atmospheric conditions and prolonged incubation time. It is important to note that the culture 
Table 1 HRMA results of patient's synovial fluids and tissues with three 16srRNA gene hypervariable regions primers (Temp_Min:80/ 90, Temp_Max:89/90)

\begin{tabular}{|c|c|c|c|c|c|c|}
\hline \multirow[t]{3}{*}{ Samples } & \multicolumn{6}{|c|}{ Detected Bacteria } \\
\hline & \multicolumn{2}{|l|}{ Culture results } & \multirow{2}{*}{$\begin{array}{l}\text { Broad- } \\
\text { range } \\
\text { PCR }\end{array}$} & \multicolumn{3}{|c|}{ HRMA $^{\mathrm{b}}\left(\mathrm{Tm}\left({ }^{\circ} \mathrm{C}\right) /\right.$ Aggregated Difference or Aggregated Distance) } \\
\hline & $\begin{array}{l}\text { Monomicrobial } \\
\text { / Polymicrobial } \\
\text { a }\end{array}$ & $\begin{array}{l}\text { Microorganisms } \\
\text { name }\end{array}$ & & V1 & V3 & V6 \\
\hline$\overline{P 1}$ & $M /-$ & S. aureus & + & S. aureus $(81.60 / 0.7)$ & S. aureus $(84.10 / 0.1)$ & S. aureus $(83.70 / 0.5)$ \\
\hline P2 & $M /-$ & S. aureus & + & S. aureus $(84.20 / 0.3)$ & S. aureus $(85.10 / 0.1)$ & S.aureus $(83.40 / 0.2)$ \\
\hline P3 & $M /-$ & S. aureus & + & S. aureus $(84.30 / 0.4)$ & S. aureus $(85.10 / 0.1)$ & S. aureus (83.00/0.2) \\
\hline P4 & $M /-$ & S. aureus & + & S. aureus (80.90/0.0) & S. aureus (84.00/0.0) & S. aureus (83.20/0.0) \\
\hline P5 & $M /-$ & S. aureus & - & S. aureus (84.70/0.8) & S. aureus (84.40/0.6) & S. aureus (83.70/0.5) \\
\hline P6 & $M /-$ & S. aureus & + & S. aureus (83.20/0.2) & S. aureus (84.90/0.1) & S. aureus (81.70/0.2) \\
\hline P7 & $M /-$ & S. epidermidis & + & S. epidermidis (83.50/0.2) & S. epidermidis (85.10/0.4) & S. epidermidis (83.70/0.1) \\
\hline P8 & $M /-$ & S. epidermidis & + & S. epidermidis (82.70/0. 2) & S.epidermidis (85.80/0.2) & S.epidermidis (83.80/0.2) \\
\hline P9 & $M /-$ & E. faecalis & + & S. epidermidis (83.10/0.6) & S. epidermidis (85.60/0.0) & S. epidermidis (83.20/0.4) \\
\hline P10 & $M /-$ & E. faecalis & + & E. faecalis (86.30/0.1) & E. faecalis (85.80/0.3) & E. faecalis (84.10/0.0) \\
\hline P11 & $M /-$ & S. haemolyticus & + & S. haemolyticus (83.80/0.1) & S. haemolyticus (87.50/0.0) & S. haemolyticus (83.80/0.5) \\
\hline P12 & $M /-$ & K. pneumoniae & + & K. pneumoniae $(86.13 / 0.03)$ & K. pneumoniae (86.80/0.7) & K. pneumoniae $(82.95 / 0.5)$ \\
\hline P13 & $M /-$ & E. coli & + & E. coli $(85.40 / 0.4)$ & E. coli $(86.20 / 0.1)$ & E. coli $(84.50 / 0.3)$ \\
\hline P14 & $M /-$ & P. aeruginosa & + & P. aeruginosa (87.50/0.5) & P. aeruginosa (85.30/0.8) & P. aeruginosa $(84.90 / 0.1)$ \\
\hline P15 & $M /-$ & B. melitensis & + & B. melitensis $(82.60 / 0.0)$ & B. melitensis $(85.40 / 0.1)$ & B. melitensis (86.40/0.4) \\
\hline P16 & $M /-$ & B. melitensis & + & B. melitensis $(82.70 / 0.1)$ & B. melitensis $(85.40 / 0.1)$ & B. melitensis (86.40/0.4) \\
\hline P17 & $-/-$ & - & + & F. magna (84.30/0. 0) & F. magna (85.50/0.0) & F. magna (82.20/0.0) \\
\hline P18 & $M /-$ & S. aureus & + & S. epidermidis (83.20/0.5) & S. epidermidis (85.20/0.3) & S. epidermidis (83.50/0.3) \\
\hline P19 & $M /-$ & S. aureus & + & S. epidermidis (83.10/0.6) & S. epidermidis (85.20/0.3) & S. epidermidis (83.80/0.0) \\
\hline P20 & $M /-$ & S. aureus & + & S. haemolyticus (83.70/0.2) & S. haemolyticus (85.90/0.0) & S. haemolyticus (83.40/0.3) \\
\hline P21 & $M /-$ & S. epidermidis & + & S. epidermidis (83.90/0.2) & S. epidermidis (85.70/0.2) & S. epidermidis (83.90/0.1) \\
\hline P22 & $M /-$ & S. aureus & + & S. aureus (83.40/0.3) & S. aureus $(85.50 / 0.0)$ & S. aureus (83.20/0.5) \\
\hline P23 & $M /-$ & S. aureus & + & S. aureus (80.94/0.54) & S. aureus (85.80/0.54) & S. aureus (82.56/0.54) \\
\hline P24 & $M /-$ & S. aureus & + & S. aureus (80.94/0.04) & S. aureus (84.10/0.1) & S. aureus (82.80/0.4) \\
\hline P25 & $M /-$ & S. epidermidis & + & S. epidermidis (82.30/0.6) & S. epidermidis (84.30/1.0) & S. epidermidis (84.10/0.4) \\
\hline P26 & $M /-$ & S. epidermidis & + & E. faecalis (86.10/0.3) & E. faecalis (84.20/0.7) & E. faecalis $(82.80 / 0.18)$ \\
\hline P27 & $M /-$ & S. epidermidis & + & S. epidermidis (83.20/0.6) & S. epidermidis (84.20/0.22) & S. epidermidis (83.60/0.81) \\
\hline P28 & $M /-$ & S. aureus & + & S. aureus $(82.10 / 1.2)$ & S. aureus (83.80/0.2) & S. aureus $(83.20 / 0.0)$ \\
\hline P29 & $M /-$ & S. epidermidis & + & E. faecalis $(86.30 / 0.1)$ & E. faecalis (85.80/0.3) & E. faecalis $(84.00 / 0.1)$ \\
\hline P30 & $M /-$ & S. epidermidis & + & S. epidermidis (80.90/0.8) & S. epidermidis (85.50/0.2) & S. epidermidis (84.20/0.5) \\
\hline P31 & $M /-$ & S. aureus & + & S. aureus (84.20/0.3) & S. aureus (85.50/0.5) & S. aureus (83.20/0.0) \\
\hline P32 & $M /-$ & S. aureus & + & S. epidermidis (81.70/0.0) & S. epidermidis (84.10/1.2) & S. epidermidis (83.80/0.1) \\
\hline P33 & $M /-$ & S. aureus & + & S. aureus (83.50/0.4) & S. aureus (80.90/0.04) & S. aureus $(82.40 / 0.1)$ \\
\hline P34 & $M /-$ & E. faecalis & + & E. faecalis $(85.89 / 0.51)$ & E. faecalis (85.47/0.53) & E. faecalis $(83.73 / 0.07)$ \\
\hline P35 & $M /-$ & S. epidermidis & + & S. epidermidis (82.60/0.1) & S. epidermidis (86.10/0.5) & S. epidermidis (83.00/0.6) \\
\hline P36 & $M /-$ & S.aureus & + & S. aureus (81.50/0.2) & S. aureus (86.10/0.3) & S. aureus (83.10/0.5) \\
\hline P37 & $M /-$ & E. faecalis & + & E. faecalis $(86.51 / 0.1)$ & E. faecalis (81.98/4.02) & E. faecalis (83.96/0.2) \\
\hline P1 & $-/ P$ & $\begin{array}{l}\text { S. epidermidis, } \\
\text { A. baumannii }\end{array}$ & + & F. magna (85.50/1.0) & F. magna (85.20/0.3) & F. magna (82.90/0.2) \\
\hline P2 & $P /-$ & S. aureus, P. mirabilis & + & S. sanguinis $(83.60 / 0.1)$ & S. sanguinis $(86.30 / 0.1)$ & S. sanguinis $(83.90 / 0.1)$ \\
\hline
\end{tabular}


Table 1 HRMA results of patient's synovial fluids and tissues with three 16srRNA gene hypervariable regions primers (Temp_Min:80/ 90, Temp_Max:89/90) (Continued)

\begin{tabular}{|c|c|c|c|c|c|c|}
\hline \multirow[t]{3}{*}{ Samples } & \multicolumn{6}{|c|}{ Detected Bacteria } \\
\hline & \multicolumn{2}{|l|}{ Culture results } & \multirow{2}{*}{$\begin{array}{l}\text { Broad- } \\
\text { range } \\
\text { PCR }\end{array}$} & \multicolumn{3}{|c|}{ HRMA $^{\mathrm{b}}\left(\mathrm{Tm}\left({ }^{\circ} \mathrm{C}\right) /\right.$ Aggregated Difference or Aggregated Distance) } \\
\hline & $\begin{array}{l}\text { Monomicrobial } \\
\text { / Polymicrobial } \\
\text { a }\end{array}$ & $\begin{array}{l}\text { Microorganisms } \\
\text { name }\end{array}$ & & $\mathrm{V} 1$ & V3 & V6 \\
\hline P3 & $P /-$ & S. aureus, C. avidum & + & C. avidum (85.80/0.1) & C. avidum (89.00/0.1) & C. avidum (85.60/0.3) \\
\hline P4 & $P /-$ & S. aureus, E. faecalis & + & S. aureus (83.90/0.2) & S. aureus $(85.90 / 0.4)$ & S. aureus (83.10/0.4) \\
\hline P5 & $P /-$ & F. magna, E. faecalis & + & F. magna (84.20/0.3) & F. magna (85.30/0.2) & F. magna $(82.70 / 0.0)$ \\
\hline P6 & $P /-$ & E.faecalis, P. mirabilis & + & F. magna $(84.20 / 0.3)$ & F. magna $(86.80 / 1.3)$ & F. magna $(82.60 / 0.1)$ \\
\hline P7 & $P /-$ & S. epidermidis, yeast & + & S. aureus (80.90/0.0) & S. aureus (84.80/0.8) & S. aureus (83.60/0.4) \\
\hline P8 & $P /-$ & E. faecalis, P. mirabilis & + & S. aureus (80.90/0.0) & S. aureus (83.30/0.7) & S. aureus (82.10/1.1) \\
\hline P9 & $P /-$ & S. aureus, P. mirabilis & + & P. mirabilis $(83.50 / 0.3)$ & P. mirabilis $(87.00 / 0.2)$ & P. mirabilis $(84.30 / 0.1)$ \\
\hline P10 & $P /-$ & E. coli, E. tarda & + & E. coli $(84.30 / 0.0)$ & E. coli (87.30/0.2) & E. coli $(84.50 / 0.1)$ \\
\hline P11 & $P /-$ & $\begin{array}{l}\text { E. coli, A. baumannii, } \\
\text { E. faecalis }\end{array}$ & + & P. mirabilis $(83.80 / 0.04)$ & P. mirabilis $(86.80 / 0.0)$ & P. mirabilis $(83.80 / 0.7)$ \\
\hline
\end{tabular}

${ }^{a}$ Multiple melting curve profiles were produced, indicating a polymicrobial infection

bHRMA, the most similar overall to reference strains

S. aureus: Staphylococcus aureus, S. epidermidis: Staphylococcus epidermidis, S. haemolyticus: Staphylococcus hemolyticus, E. faecalis: Enterococcus faecalis, S. sanguinis: Streptococcus sanguinis, C. avidum: Cutibacterium avidum, F. magna: Finegoldia magna, B. melitensis: Brucella melitensis, E. coli: Escherichia coli, P. mirabilis: Proteus mirabilis, E. tarda: Edwardsiella tarda, P. aeruginosa: Pseudomonas aeruginosa, A. baumannii: Acinetobacter baumannii

results were positive for a significant percentage of patients who had taken antibiotics before sampling (23.4\%, $11 / 47$ cases). Positive culture results may be owing to the use of optimal conditions. Of the 16 suspected culturenegative PJIs who met the consensus criteria, three cases
(18.75\%) receiving empirical antibiotic therapy before sampling, as expected, taking antibiotics has resulted in negative cultures.

Yoon et al. in a review study reported that the prevalence of culture-negative PJIs are up to $42 \%$ [10].

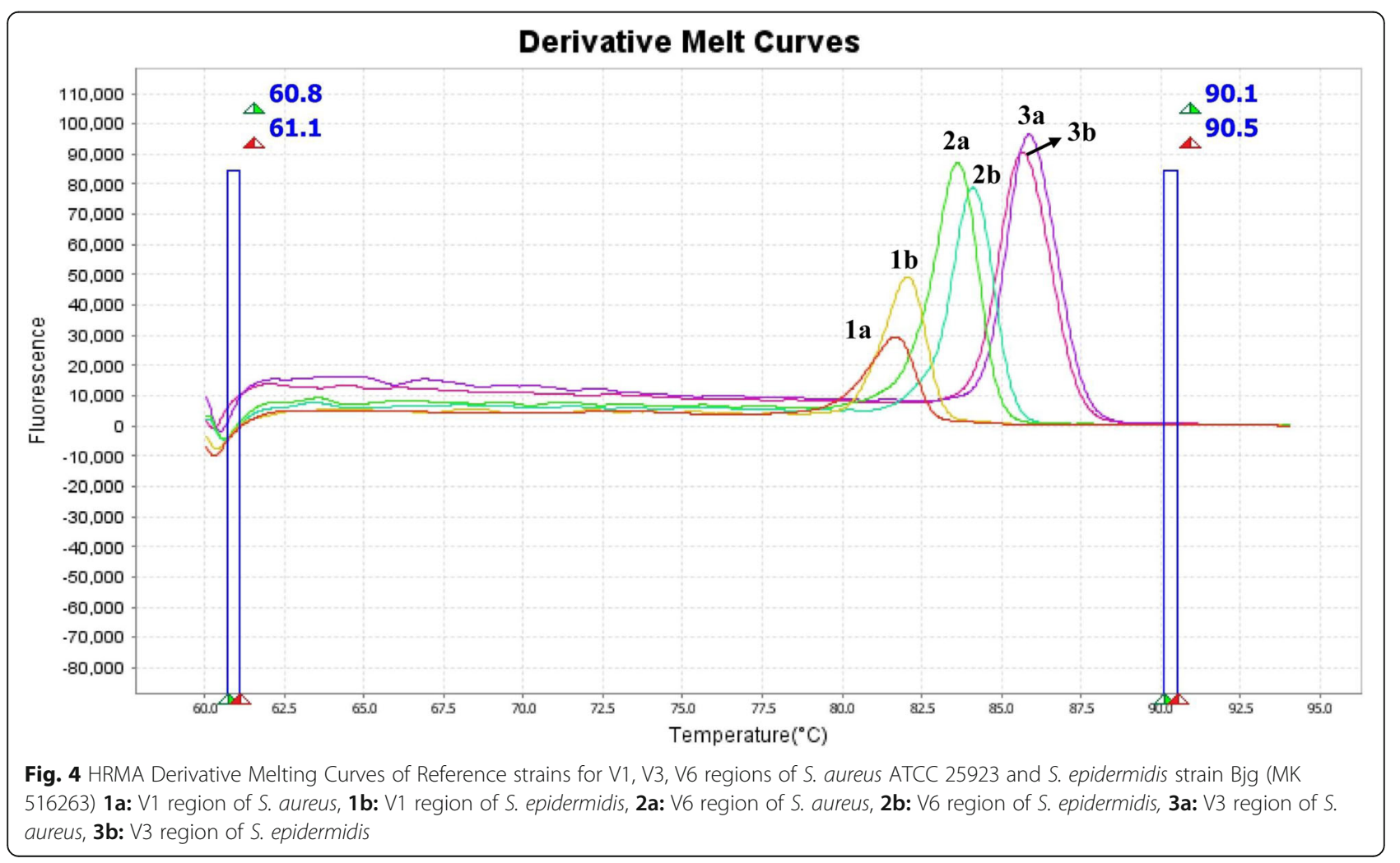


Moshirabadi et al. from Iran reported that the incidence of negative culture in PJIs are as high as 68\% [20]. Kim et al. reported that the incidence of negative culture outcome was $42 \%$ in knee PJIs which was significantly higher compared to other published studies [21]. In the study of Bejon et al., frequent of culture-negative infection was $41 \%$, and of these, $93 \%$ taking a minimum of 14 days' antibiotic-free gap before sampling [22].

Our data show improving the culture method can be effective in increasing the positive cultures among antibiotic users, to some extent. Overall, our results revealed that the most common bacteria isolated from PJIs were Gram-positive cocci, with S. aureus (36.17\%) and CoNS (29.78\%) being the most prevalent. In most of the studies, Gram-positive cocci are involved in the majority of hip and knee PJIs. This is driven largely by infection with $S$. aureus and CoNS [23, 24]. MRS spp., especially $S$. aureus and $S$. epidermidis, will impose unnecessary antibiotic selection pressures and also, additional costs on treating patients [22]. In our evidence, the percentage of MRS isolates was $25.53 \%$ in which $10.63 \%$ S. aureus and $14.89 \%$ CoNS were methicillin resistance. It comprised about one-third of all cases (17/47). There is no report on the prevalence of MRS PJIs in our country and it seems that it was consistent with the prevalence of MRS in some studies $[25,26]$. A study by Uckay et al. revealed $45(75 \%)$ of the orthopedic infections caused by CoNS were MR-CoNS strains [27]. Among 47 PJIs during our study period, 11 (23.4\%) cases were due to Enterococcus spp. and of these, two (4.25\%) cases were related to VRE. Berbar et al. reported Enterococcus spp. accounts for only $3 \%$ of PJI [28]. In Ortega et al. study was showed that none of the Enterococcus spp. were resistant to vancomycin [29]. Our evidence revealed monomicrobial PJIs were more frequent than polymicrobial PJIs and accounted for $76.59 \%$ (36 of 47 cases) and 23.4\% (11 of 47 cases, respectively. However, the prevalence of polymicrobial infection is high in our findings compared to most other studies [30,31]. Hence, a high incidence of polymicrobial infections should be noticed in treatment of PJIs. Tan et al. reported 10.3\% (108 of 1045) of the PJIs treated at their institution were polymicrobial [30]. In this study Enterococcus species, S. aureus, and aerobic Gram-negative bacilli, including E. coli, are the most frequently isolated bacteria in polymicrobial PJIs, also the frequency of other Gram- negative organisms was higher in polymicrobial PJIs than in monomicrobial PJIs. It should be mentioned that patients with a polymicrobial PJI had higher treatment failure which may be related to Gram-negative PJIs [31]. The anaerobic bacteria are identified rarely and are one of the significant causative agents of PJIs. In the present study, 6.38\% (3/ 47) of PJIs were an anaerobic infection caused by two isolates of F. magna and one C. avidum. Khosravi et al. reported the prevalence of anaerobes in PJIs was 1.9\% [32]. Soderquist et al. identified F. magna isolates from nine patients from 2004 to 2016 [33]. Zeller et al. revealed among 1179 PJIs treated during the study period, 15 (1\%) PJIs were due to C.avidum which were isolated from patients with hip arthroplasty [34].

Broad-range PCR is useful for rapid reports of unknown bacterial pathogens presence in patient's clinical specimens especially for whom are infection-suspicion and culture-negative.

The broad-range PCR specifies only bacterial DNA presence in specimens which is a disadvantage of PCR and this problem can resolve with HRMA. This study showed that broad-range PCR was able to detect bacterial DNA in $97.87 \%(46 / 47)$ of culture-positive samples. Also in one negative culture case, broad-range PCR was positive, therefore the results of culture and broad-range PCR were not in agreement with each other only in two cases. This finding is consistent with Rampini et al. results that showed a high concordance of $90 \%$ for broadrange PCR and culture [35]. Fifty percent concordance for cultivation and broad-range PCR was observed in Akram et al. study [3]. The results of PCR and HRMA was positive only for one negative culture case, in which F. magna was detected which confirmed by $16 \mathrm{~s} r R N A$ gene sequencing [36].

At our experiment, 16srRNA gene HRMA was found to be able of organism identification in $91.89 \%$ (34/37) of patients which were concordant with monomicrobial culture results (four cases were accordant at the genus level) and 8.1\% (3/37) of HRMA results were discordant with culture. It is likely that these infections were polymicrobial, with only one of the pathogens was identified by culture and, the other causative agent distinguished by HRMA, due to HRMA's inability to resolve polymicrobial infections. In confirmation of this, in $3 / 37$ discordant samples, HRMA generated multiple melting peaks in their derivative plots. Our finding is consistent with Won et al. study that evaluated a broad-based PCR assay coupled with HRMA for bacterial identification in bacterial septic patients (52 cases). Their assay results were concordant with culture findings in 46/52 (88.5\%) [37].

In our study, of 47 (mono + poly) cases, 41 (87.23\%) cases were detected by HRMA. The sensitivity and specificity of total HRMA (mono + poly) vs culture were 82.92, 93.75\%., respectively. Hardick et al. showed that HRMA concordance with species identification of bacterial pathogens in ascitic fluids from patients with suspected spontaneous bacterial peritonitis (mono+poly) was $70.6 \%$ and the following sensitivity and specificity for 16S PCR-HRMA compared with culture techniques were 100 and $91.5 \%$, respectively [38].

The main reason for the decrease in the sensitivity of total HRMA in our study is the inability of HRMA 
method in the detection of bacteria associated with polymicrobial infections.

In the present study, multiple hypervariable regions melt curve profiles of clinical strains were compared with reference strains using the Matlab-2018b program. Nevertheless, in polymicrobial infections, HRMA generated multiple dominant peaks in the derived melting curves. The Matlab-2018b program evidently supported HRMA to correctly identified individual bacterial species from polymicrobial samples (7/11) in this study. Therefore, presence multiple melting peaks in their derivative plots can suggest the presence of multiple pathogens that aiding in antibiotic selection for suspected polymicrobial infections. Won et al. had problems with polymicrobial infections and HRMA generated multiple melting peaks in their plots accordance with our study [37]. It should be noted that the probability of sample contamination should be considered when multiple melting peaks are obtained. The appropriate programs such as the Matlab-2018b program are effective for analyzing HRMA data similar to published studies by Athamanolap et al. [39]. Finally, although the identification of bacteria by conventional methods are time-consuming, the culture method is relatively practical for the identification of bacteria and unlike most molecular methods, antibiotic susceptibility can be determined by the culture method. However, some factors such as false-negative culture, slow-growing pathogens, the formation of biofilm and antibiotic prophylaxis reduce the accuracy of the culture method in identifying bacteria. It can be concluded that molecular techniques such as broad-range PCR and HRMA are complementary to this method for organism identification. Some of the investigators used different molecular techniques such as polymerase chain reaction-restriction fragment length polymorphism (PCR-RFLP) technique and new technology of NextGeneration Sequencing (NGS) to detect PJI [12, 20]. Despite the advantages of these techniques for the identification of causative organisms in PJI, significant challenges are addressed below; the PCR-RFLP technique is a gel-based and time-consuming process and large amounts of DNA required [40]. While NGS technique is costly, it does not require isolation of a pure bacteria species [41].

According to the descriptions given about culture method and HRMA, as well as their advantages and disadvantages, culture method as a Gold standard method along with a molecular method such as HRMA, to accelerate the response in laboratory will be many helpful.

The main limitation of this study was related to PCRHRMA which is its inability to resolve polymicrobial infections. In HRMA assay, polymicrobial PJIs can be detected with respect to multiple dominant peaks in the derivate melting curve, but the individual causative agents responsible for polymicrobial PJIs cannot be correctly diagnosed by our assay $[37,38]$. Nonetheless, in the current study, three discrepant samples with monomicrobial growth by culture were observed to have multiple organisms by PCR-HRMA. These results imply either contamination or a potential benefit of PCRHRMA than conventional cultural methods to determine the presence of polymicrobial identifications. Identifying the pathogens at an earlier time point is a significant clinical benefit and help to prompt treatment [38].

In order to resolve the problem of polymicrobial PJIs identification, the use of universal digital PCR and highresolution melt along with developed Nanoarray is suggested [42]. In HRM assay, if the causative agents of infections are not present in reference strains library, it is not detectable by the HRMA. Consequently, we recommend a vast reference strains library. Other PCRHRMA limitations were exchanges in DNA base pairs. Changes in Tm: approx. $0.8-1.4{ }^{\circ} \mathrm{C}$ and more were performed by exchange between DNA G: C and T: A base pairs, this range and lower than this temperature range were considered as one type of bacteria [43]. Hence, in our study, the Tm difference index of HRMA was considered $0-1.4{ }^{\circ} \mathrm{C}$ which more than this range were discrepant samples with culture findings and reference strains library. Owning to the limited range of a 96-well microtiter plate, in the Real-time PCR instruments and software, it is not able to process and comparing reference strains with clinical samples for three 16SrRNA gene regions across all rounds, entirely. We optimized the problem with the Matlab-2018b program [39].

\section{Conclusion}

The present evidence demonstrates HRM assay is an effective screening approach to identify the pathogens involved in PJIs especially in aiding culture method. This knowledge is revealed that the HRMA is a technique of single step, rapid and relatively cost-effective. This approach can detect DNA in different clinical specimens directly extracted from PJI samples. Data analysis using Matlab-2018b program was valuable and practical to compare between detected organisms and reference strains. Using the HRMA approach and data analysis by the Matlab-2018b, monomicrobial PJIs in agreement with culture findings gained better results than polymicrobial PJIs. Future advances in this field should focus on approaches for definitive diagnosis of the causative organisms in polymicrobial PJIs identification.

\section{Material and methods}

\section{Study design and population}

In this study between August 2017 and November 2019, 63 patients (42 women and 21 men) aged 41-85 years were qualified. The specimens (39 synovial fluids and 24 
tissues from knee and hip joint) were taken from patients who underwent knee and hip joint surgeries in PJIs (63 cases) under observing tertiary care hospitals located in Tehran, Iran. Patients characteristics were documented according to the involved joints (hip and knee), age, gender, inflammatory markers (CRP, ESR), white blood cell, fever, antibiotic consumption (in $\leq 2$ to 4 weeks preceding surgery) [21].

\section{Case definition}

The cases included in this study belonged to the PJIs (63 cases). The patients who had one or two major criteria for PJI based on PCC, the first, two positive cultures of the same pathogens or the second, a sinus tract in association with the joint - and/or had two or three of the following minor criteria - raised up serum CRP and ESR (with abnormal values of $>10 \mathrm{mg} / \mathrm{ml}$ and $>30 \mathrm{~mm} / \mathrm{h}$, respectively), raised up synovial leukocyte count or raised up synovial neutrophil percentage (with abnormal values and percentage of $>1700 \mathrm{cell} / \mu \mathrm{l}$ and $>65 \%$ respectively, for knees and $>3000$ cells $/ \mu$ l and $>80 \%$, respectively, for hips were considered abnormal) were considered as cases of PJI [20, 21, 44-46].

\section{Microbiological culture and biochemical testing approaches}

The synovial fluid and tissue specimens were taken during aspiration and knee and hip joint surgery. Specimens were cultured on both of the broth (such as thioglycolic acid, brain heart infusion broth, and resin-containing BACTEC Blood Culture Media) and agar medium (such as brain heart infusion, blood, chocolate, MacConkey, and schaedler agar supplemented with Vitamin K1) in $37^{\circ} \mathrm{C}$ for at least $48 \mathrm{~h}$ under aerobic, microaerophilic (with $5-7 \% \mathrm{CO} 2)$ and anaerobic conditions. The incubation period was extended to 14-21 days for slow-growing and fastidious microorganisms. The identification of isolated organisms was done by biochemical tests [47] and were confirmed with VITEK 2 Compact system (BioMerieux, USA). Vancomycin minimum inhibitory concentrations were determined by the E-test method (MIC test strip, liofilchem, Italy) for MRS ssp. Additionally, VRE was determined using the disk diffusion test.

\section{Extraction of nucleic acids}

DNA extraction of 63 specimens (For each patient, one synovial fluid specimen was included and tissue specimen was included for patients who had no synovial fluid) was done by Qiagen kit (QIAamp DNA Mini Kit, Germany). The quality and quantity of the extracted DNA were assayed by spectrophotometry at 260 and $280 \mathrm{~nm}$ UV-vis light. Extracted DNA was stored at $20^{\circ} \mathrm{C}$ for the PCR and HRMA [20].

\section{Broad-range PCR}

The 16SrRNA PCR of 63 specimens was achieved by universal primers (27F: AGAGTTTGATCCTGGC TCAG, 1429R: GGTTACCTTGTTACGACTT) [35]. PCR reactions were performed in $25 \mu \mathrm{l}$ final concentration: $10 \mu \mathrm{l}$ of the master mix, $0.5 \mu \mathrm{l}$ of $25 \mathrm{pmol} F$ primer, $0.5 \mu \mathrm{l}$ of $25 \mathrm{pmol} \mathrm{R}$ primer, $12 \mu \mathrm{l}$ sterile distilled water and $2 \mu \mathrm{l}$ genomic DNA. PCR conditions were $95^{\circ} \mathrm{C}$ for $300 \mathrm{~s}$, followed by 37 cycles of $95^{\circ} \mathrm{C}$ for $45 \mathrm{~s}, 58^{\circ} \mathrm{C}$ for 30 s (annealing temperature), $72^{\circ} \mathrm{C}$ for 70 s and final extension $72^{\circ} \mathrm{C}$ for $300 \mathrm{~s} \mathrm{[14]}$.

\section{The HRMA of 165 rRNA gene hypervariable regions}

The $16 S$ rRNA HRMA (Applied Biosystems Step OnePlus Systems, USA) was performed for samples with positive broad-range PCR (48 synovial fluid and tissue samples) and of these, one sample was with a positive culture and negative broad-range PCR.

At first, HRMA was done with extracted DNA of 19 species of bacteria (reference strains) which are associated with PJIs. By targeting V1, V3, and V6 hypervariable regions, each of species had a specific melting curve group consist of three melting curves. Finally, a melting curve library was prepared to depend on reference strains. In the following, HRMA was done with extracted DNA of synovial fluid and tissue samples and then melting curve data generated from each of the samples were compared to the melting curve library of reference strains [14, 21, 48]. Reference strains used in this study were S. aureus ATCC 29213, S. aureus ATCC 25923, S. epidermidis strain Bjg (MK 516263), S. hemolyticus ATCC 29970, S. saprophyticus ATCC 15305, Micrococcus luteus ATCC 15307, Enterococcus faecalis ATCC 29212, Streptococcus sanguinis ATCC 10566, Finegoldia magna ATCC 1766, Cutibacterium ATCC 25573, Haemophilus influenza ATCC 49766, Pseudomonas aeruginosa 27,853, Escherichia coli ATCC 25922, Klebsiella pneumonia ATCC 700603, Proteus mirabilis ATC 43071, Acinetobacter baumannii ATCC 19606, Brucella melitensis 16 M ATCC 23456, Mycobacterium tuberculosis H37Rv, Corynebacterium simulans strain BJd (MK 516260).

HRMA reactions were performed in a $20 \mu \mathrm{l}$ final volume and contained the following final concentrations: $4 \mu \mathrm{l}$ of $5 \mathrm{x}$ EvaGreen master mix (5x HOT FIREPol EvaGreen HRM Mix by Solis BioDyne), $0.6 \mu \mathrm{l}$ of $10 \mathrm{pmol} \mathrm{F}$ primer, $0.6 \mu \mathrm{l}$ of $10 \mathrm{pmol} \mathrm{R}$ primer (Table 2), $13.8 \mu \mathrm{l}$ sterile deionized water and $1 \mu \mathrm{l}$ genomic DNA (each of three primer pairs were in three reactions, individually). PCR and HRMA conditions were $95^{\circ} \mathrm{C}$ for $300 \mathrm{~s}$, followed by 40 cycles of $95^{\circ} \mathrm{C}$ for $10 \mathrm{~s}, 58^{\circ} \mathrm{C}$ for 30 s (annealing temperature), and $72^{\circ} \mathrm{C}$ for $10 \mathrm{~s}$ and melt curve stage with $95^{\circ} \mathrm{C}$ for $15 \mathrm{~s}, 60^{\circ} \mathrm{C}$ for $60 \mathrm{~s}, 95^{\circ} \mathrm{C}$ for $15 \mathrm{~s}$. Some of the HRMA-positive samples were confirmed by DNA 
Table 2 Primers targeting the bacterial 16S rRNA gene for HRMA

\begin{tabular}{llll}
\hline Region & Primer & Sequence $\left.\mathbf{( 5}^{\prime}-\mathbf{3}^{\prime}\right)$ & Product size (bp) \\
\hline V1 & V1-F & GYGGCGNACGGGTAGTAA & 170-171 \\
& V1-R & TIACCCACCAACTAGC & \\
V3 & V3-F & CCAGACTCCTACGGGAGGCAG & $204-205$ \\
V3-R & CGTATTACCGCGGTGCTG & \\
V6 & V6-F & TGGAGCATGTGGTTAATTCGA & $128-131$ \\
& V6-R & AGCTGACGACANCCATGCA & \\
\hline
\end{tabular}

sequencing and recorded in the nucleotide database in NCBI.

\section{Processing for HRMA results by Matlab-2018b program}

To assay HRM, experimentally produced reference strains and clinical isolates melting curves (raw melting data files) were exported from Step One software v2.3 and imported into Matlab-2018b program, where the melting curves were first translated with a translation function and afterward compared with the melting curve database produced in reference strains in each hypervariable region of $16 s r R N A$ gene (V1, V3, V6), individually. A reference library based on Tm and melting curves of 19 reference strains was established for the identification of pathogens. The Matlab program consists of three main parts, reading data from exported raw data files and preprocessing, analyzing data and assigning most similar reference strains to each clinical isolate, and writing the answers to the file and visualizing.

In the beginning, the program was written with the relevant codes and was executed by Matlab-2018b then was classified as different clinical isolates and reference strains. In the following, their melting curves and Tm were compared to each other for organism's identification [39]. Herein, programming, processing, and analyzing were performed by the designed program based on hypervariable regions of the 16srRNA gene with temperature range between $80.90{ }^{\circ} \mathrm{C}-89.90^{\circ} \mathrm{C}$ (based on obtained reference strains $\mathrm{Tm})$. Detection criteria in Matlab-2018b analysis are based on a comparison of reference strains to correspond Tm with the closest clinical isolate Tm (for every three regions of the gene with different primers, individually). Indeed, Tm differentiation distances between the reference strains and clinical isolates were indicated with an aggregated difference index $\left(0{ }^{\circ} \mathrm{C}-1.4^{\circ} \mathrm{C}\right)$ [43]. Tm peaks belong to $16 s r R N A \mathrm{~V} 1, \mathrm{~V} 3$ and $\mathrm{V} 6$ regions in reference strains and clinical strains were compared with each other in this program, and the final results were taken according to the closet similarity between these two groups.

In our study, sensitivity, specificity, PPV, NPV, and accuracy were calculated for HRMA vs culture based on the PCC definition of PJIs.

\begin{abstract}
Abbreviations
PJl: Periprosthetic joint infection; PCC: Philadelphia Consensus Criteria; HRMA: High-Resolution Melt Analysis; Tm: Melting temperature; PPV: Positive predictive values; NPV: Negative predictive values; S. aureus: Staphylococcus aureus; CoNS: Coagulase-negative staphylococci; F.magna: Finegoldia magna; C. avidum: Cutibacterium avidum; MRS spp.: Methicillin-resistant Staphylococcus spp.; MRSA: Methicillin-resistant Staphylococcus aureus; MRSE: Methicillin-resistant Staphylococcus epidermidis; VRE: Vancomycinresistant enterococci
\end{abstract}

\section{Acknowledgments}

This study was supported by Tehran University of Medical Sciences, Iran, Tehran.

Authors' contributions

FJ, ME, and SB designed the study. SB performed sampling, practical and molecular methods. ME contributed to draft the manuscript. MJ, SMM, MT and, ASv contributed to sampling. AT performed data analysis. RB contributed to molecular methods. All authors reviewed and approved the manuscript.

\section{Funding}

This research has been supported by Tehran University of Medical Sciences \& health Services (grant code: 96-03-30-36067).

Availability of data and materials

All documents and additional data are available from the corresponding author upon reasonable request.

\section{Declarations}

\section{Ethics approval and consent to participate}

The Ethics Committee of Tehran University of Medical Sciences, Tehran, Iran (approval number: IR.TUMS.MEDICINE.REC.1396.3906) approved this study, and the study was performed in accordance with the approved guidelines. Before participating, all patients signed an informed consent form regarding the aims of the study and willingness to participate. For pathogens isolated, we did not have human participants and the study used bacteria isolated from clinical specimens in the clinical microbiology laboratory.

\section{Consent for publication}

Not applicable.

\section{Competing interests}

The authors declare that they have no conflict of interest.

\section{Author details}

${ }^{1}$ Department of Microbiology, School of Medicine, Tehran University of Medical Sciences, Tehran, Iran. ²Department of Orthopedic Surgery, Shafa Yahyaiyan Hospital, Iran University of Medical Sciences, Tehran, Iran. ${ }^{3}$ Department of Orthopedic Surgery, Imam Khomaini Hospital, Tehran University of Medical Sciences, knee and hip surgeon, Tehran, Iran. ${ }^{4}$ School of Electrical and Computer engineering, college of engineering, University of Tehran, Tehran, Iran. 


\section{Received: 30 January 2021 Accepted: 22 March 2021}

\section{Published online: 13 April 2021}

\section{References}

1. Zimmerli W. Bone and joint infections : from microbiology to diagnostics and treatment. Hoboken: Wiley; 2015.

2. Lenguerrand $E$, Whitehouse MR, Beswick AD, Kunutsor SK, Foguet P, Porter $M$, et al. Risk factors associated with revision for prosthetic joint infection following knee replacement: an observational cohort study from England and Wales. Lancet Infec Dis. 2019;19(6):589-600. https://doi.org/10.1016/S14 73-3099(18)30755-2.

3. Akram A, Maley M, Gosbell I, Nguyen T, Chavada R. Utility of 165 rRNA PCR performed on clinical specimens in patient management. Int J Infet Dis. 2017:57:144-9. https://doi.org/10.1016/j.jijid.2017.02.006.

4. Liu XW, Zi Y, Xiang LB, Wang Y. Total hip arthroplasty: areview of advances, advantages and limitations. Int J Clin Exp Med. 2015;8(1):27-36.

5. Huang R, Adeli B, Mortazavi J, Parvizi J, Hu CC. Culture-negative periprosthetic joint infection does not preclude infection control hip. Clin Orthop Relat Res. 2012;470(10):2717-23. https://doi.org/10.1007/s11999012-2434-0.

6. Wouthuyzen-Bakker M, Sebillotte M, Lomas J, Kendrick B, Palomares EB, Murillo $\mathrm{O}$, et al. Timing of implant-removal in late acute periprosthetic joint infection: a multicenter observational study. J Inf Secur. 2019;79(3):199-205.

7. Kiran M, Donnelly TD, Armstrong C, Kapoor B, Kumar G, Peter V. Diagnostic utility of fluorodeoxyglucose positron emission tomography in prosthetic joint infection based on MSIS criteria. Bone Joint J. 2019:101-b(8):910-4.

8. Bozhkova S, Tikhilov R, Labutin D, Denisov A, Shubnyakov I, Razorenov V, et al. Failure of the first step of two-stage revision due to polymicrobial prosthetic joint infection of the hip. J Orthop Traumatol. 2016;17(4):369-76. https://doi.org/10.1007/s10195-016-0417-8.

9. Mahieu R, Dubee $V$, Seegers $V$, Lemarie $C$, Ansart $S$, Bernard L, et al. The prognosis of streptococcal prosthetic bone and joint infections depends on surgical management-a multicenter retrospective study. Int J Infet Dis. 2019; 85:175-81. https://doi.org/10.1016/j.jijid.2019.06.012

10. Yoon HK, Cho SH, Lee DY, Kang BH, Lee SH, Moon DG, et al. A review of the literature on culture-negative Periprosthetic joint infection: epidemiology, diagnosis and treatment. Knee Surg Relat Res. 2017;29(3): 155-64. https://doi.org/10.5792/ksrr.16.034.

11. Ferreira MC, Oliveira JCP, Zidan FF, Franciozi C, Luzo MVM, Abdalla RJ. Total knee and hip arthroplasty: the reality of assistance in Brazilian public health care. Rev Bras Ortop. 2018;53(4):432-40. https://doi.org/1 0.1016/j.rbo.2016.11.002

12. Tarabichi M, Shohat N, Goswami K, Alvand A, Silibovsky R, Belden K, et al. Diagnosis of Periprosthetic joint infection: the potential of next-generation sequencing. Rev Bras Ortop. 2018;100(2):147-54.

13. Street TL, Sanderson ND, Atkins BL, Brent AJ, Cole K, Foster D, et al. Molecular diagnosis of orthopedic-device-related infection directly from sonication fluid by metagenomic sequencing. J Clin Microbiol. 2017;55(8): 2334-47. https://doi.org/10.1128/JCM.00462-17.

14. Jeng K, Yang S, Won H, Gaydos CA, Hsieh YH, Kecojevic A, et al. Application of a $16 \mathrm{~S}$ rRNA PCR-high-resolution melt analysis assay for rapid detection of Salmonella bacteremia. J Clin Microbiol. 2012;50(3):1122-4. https://doi.org/1 0.1128/JCM.05121-11.

15. Yang B, Wang Y, Qian PY. Sensitivity and correlation of hypervariable regions in 165 rRNA genes in phylogenetic analysis. BMC Bioinformatics. 2016;17(1):135. https://doi.org/10.1186/s12859-016-0992-y.

16. Landolt P, Stephan R, Scherrer S. Development of a new high resolution melting (HRM) assay for identification and differentiation of Mycobacterium tuberculosis complex samples. Sci Rep. 2019;9(1):1850. https://doi.org/10.103 8/s41598-018-38243-6.

17. Tong SY, Giffard PM. Microbiological applications of high-resolution melting analysis. J Clin Microbiol. 2012;50(11):3418-21. https://doi.org/10.1128/JCM. 01709-12.

18. Hjelmso MH, Hansen LH, Baelum J, Feld L, Holben WE, Jacobsen CS. Highresolution melt analysis for rapid comparison of bacterial community compositions. Appl Environ Microbiol. 2014;80(12):3568-75. https://doi.org/1 0.1128/AEM.03923-13.

19. Fraley SI, Athamanolap P, Masek BJ, Hardick J, Carroll KC, Hsieh YH, et al. Nested machine learning facilitates increased sequence content for largescale automated high resolution melt genotyping. Sci Rep. 2016;6(1):19218. https://doi.org/10.1038/srep19218.
20. Moshirabadi A, Razi M, Arasteh P, Sarzaeem MM, Ghaffari S, Aminiafshar S, et al. Polymerase chain reaction assay using the restriction fragment length polymorphism technique in the detection of prosthetic joint infections: a multi-centered study. J Arthroplast. 2019;34(2):359-64. https://doi.org/10.101 6/j.arth.2018.10.017.

21. Kim YH, Kulkarni SS, Park JW, Kim JS, Oh HK, Rastogi D. Comparison of infection control rates and clinical outcomes in culture-positive and culturenegative infected total-knee arthroplasty. J Orthop. 2015;12(Suppl 1):S37-43. https://doi.org/10.1016/j.jor.2015.01.020.

22. Bejon P, Berendt A, Atkins BL, Green N, Parry H, Masters S, et al. Two-stage revision for prosthetic joint infection: predictors of outcome and the role of reimplantation microbiology. J Antimicrob Chemother. 2010;65(3):569-75. https://doi.org/10.1093/jac/dkp469.

23. Tande AJ, Patel R. Prosthetic joint infection. Clin Microbiol Rev. 2014;27(2): 302-45. https://doi.org/10.1128/CMR.00111-13.

24. Flurin L, Greenwood-Quaintance KE, Patel R, Patel R. Microbiology of polymicrobial prosthetic joint infection. Diagn Microbiol Infect Dis. 2019; 94(3):255-9. https://doi.org/10.1016/j.diagmicrobio.2019.01.006.

25. Tafer N, Belaieff W, Cuérel C, Zingg M, Hoffmeyer P, Uçkay I. Optimal diagnosis, prevention, and management of periprosthetic joint infection. Orthop Res Rev. 2015:2015(7):11-9.

26. Pulido L, Ghanem E, Joshi A, Purtill JJ, Parvizi J. Periprosthetic joint infection: the incidence, timing, and predisposing factors. Clin Orthop Relat Res. 2008; 466(7):1710-5. https://doi.org/10.1007/s11999-008-0209-4.

27. Uckay I, Harbarth S, Ferry T, Lubbeke A, Emonet S, Hoffmeyer P, et al. Meticillin resistance in orthopaedic coagulase-negative staphylococcal infections. J Hosp Infect. 2011;79(3):248-53. https://doi.org/10.1016/j.jhin.2 011.06.014.

28. Berbari EF, Osmon DR, Carr A, Hanssen AD, Baddour LM, Greene D, et al. Dental procedures as risk factors for prosthetic hip or knee infection: a hospital-based prospective case-control study. Clin Infect Dis. 2010;50(1):816. https://doi.org/10.1086/648676

29. Ortega-Pena S, Colin-Castro C, Hernandez-Duran M, Lopez-Jacome E, Franco-Cendejas R. Microbiological characteristics and patterns of resistance in prosthetic joint infections in a referral hospital. Cir Cir. 2015;83(5):371-7. https://doi.org/10.1016/j.circen.2015.10.002.

30. Tan TL, Kheir MM, Tan DD, Parvizi J. Polymicrobial Periprosthetic joint infections: outcome of treatment and identification of risk factors. J Bone Joint Surg Am. 2016;98(24):2082-8. https://doi.org/10.2106/JBJS.15.01450.

31. Tsai $Y$, Chang $\mathrm{CH}$, Lin YC, Lee $\mathrm{SH}$, Hsieh PH, Chang Y. Different microbiological profiles between hip and knee prosthetic joint infections. J Orthop Surgery (Hong Kong). 2019;27(2):2309499019847768.

32. Khosravi AD, Ahmadi F, Salmanzadeh S, Dashtbozorg A, Montazeri EA. Study of Bacteria isolated from orthopedic implant infections and their antimicrobial susceptibility pattern. Res J Microbiol. 2009;4(4):158-63. https://doi.org/10.3923/jm.2009.158.163

33. Soderquist B, Bjorklund $\mathrm{S}$, Hellmark B, Jensen A, Bruggemann H. Finegoldia magna isolated from orthopedic joint implant-associated infections. J Clin Microbiol. 2017:55(11):3283-91. https://doi.org/10.1128/JCM.00866-17.

34. Zeller VA, Letembet VA, Meyssonnier VA, Heym B, Ziza JM, Marmor SD. Cutibacterium (formerly Propionibacterium) avidum: a rare but avid agent of prosthetic hip infection. J Arthroplast. 2018;33(7):2246-50. https://doi.org/1 0.1016/j.arth.2018.02.008.

35. Rampini SK, Bloemberg GV, Keller PM, Buchler AC, Dollenmaier G, Speck RF, et al. Broad-range 165 rRNA gene polymerase chain reaction for diagnosis of culture-negative bacterial infections. Clin Infect Dis. 2011;53(12):1245-51. https://doi.org/10.1093/cid/cir692.

36. Arsene C, Saste A, Somiah M, Mestrovich J, Berger G. A case of septic arthritis of the wrist due to Finegoldia magna. Case Rep Infect Dis. 2014;2014:1-4

37. Won H, Rothman R, Ramachandran P, Hsieh YH, Kecojevic A, Carroll KC, et al. Rapid identification of bacterial pathogens in positive blood culture bottles by use of a broad-based PCR assay coupled with high-resolution melt analysis. J Clin Microbiol. 2010;48(9):3410-3. https://doi.org/10.1128/ JCM.00718-10.

38. Hardick J, Won H, Jeng K, Hsieh YH, Gaydos CA, Rothman RE, et al. Identification of bacterial pathogens in ascitic fluids from patients with suspected spontaneous bacterial peritonitis by use of broad-range PCR (16S P(R) coupled with high-resolution melt analysis. J Clin Microbiol. 2012;50(7): 2428-32. https://doi.org/10.1128/JCM.00345-12.

39. Athamanolap $P$, Hsieh $K$, Chen L, Yang S, Wang TH. Integrated bacterial identification and antimicrobial susceptibility testing using PCR and high- 
resolution melt. Anal Chem. 2017;89(21):11529-36. https://doi.org/10.1021/a cs.analchem.7b02809.

40. Jadaon MM, Dashti AA, Lewis HL, Habeeb FM. Whole-blood polymerase chain reaction and restriction fragment length polymorphism: a simplified method by microwave irradiation. Med Princ Pract. 2009;18(4):280-3. https:// doi.org/10.1159/000215724.

41. Gu W, Miller S, Chiu CY. Clinical metagenomic next-generation sequencing for pathogen detection. Annu Rev Pathol. 2019;14(1):319-38. https://doi. org/10.1146/annurev-pathmechdis-012418-012751.

42. Athamanolap P, Hsieh K, O'Keefe CM, Zhang Y, Yang S, Wang J. Machine learning-assisted digital PCR and melt enables broad Bacteria identification and Pheno-molecular antimicrobial susceptibility test. Anal Chem. 2019; 91(20):12784-92. https://doi.org/10.1021/acs.analchem.9b02344.

43. Luthra R, Singh RR, Patel KP. Clinical applications of PCR. 3 Springer Science and Business Media New York: Humana Press; 2018.

44. Gomez E, Cazanave C, Cunningham SA, Greenwood-Quaintance KE, Steckelberg JM, Uhl JR, et al. Prosthetic joint infection diagnosis using broad-range PCR of biofilms dislodged from knee and hip arthroplasty surfaces using sonication. J Clin Microbiol. 2012;50(11):3501-8. https://doi. org/10.1128/JCM.00834-12.

45. Parvizi J, Tan TL, Goswami K, Higuera C, Della Valle C, Chen AF, et al. The 2018 Definition of Periprosthetic Hip and Knee Infection: An Evidence-Based and Validated Criteria. J Arthroplasty. 2018;33(5):1309-1314.e1302.

46. Parvizi J, Zmistowski B, Berbari EF, Bauer TW, Springer BD, Della Valle CJ, et al. New definition for periprosthetic joint infection. J Arthroplast. 2011; 26(8):1136-8.

47. Forbes BA, Sahm DF, Weissfeld AS. Study guide for "Bailey \& Scott's diagnostic microbiology". 12th ed. St Louis: Mosby; 2007.

48. Fraley SI, Hardick J, Masek BJ, Athamanolap P, Rothman RE, Gaydos CA, et al. Universal digital high-resolution melt: a novel approach to broad-based profiling of heterogeneous biological samples. Nucleic Acids Res. 2016;44(1): 508. https://doi.org/10.1093/nar/gkv1083.

49. Yang S, Ramachandran P, Rothman R, Hsieh YH, Hardick A, Won H, et al. Rapid identification of biothreat and other clinically relevant bacterial species by use of universal PCR coupled with high-resolution melting analysis. J Clin Microbiol. 2009;47(7):2252-5. https://doi.org/10.1128/JCM. 00033-09.

\section{Publisher's Note}

Springer Nature remains neutral with regard to jurisdictional claims in published maps and institutional affiliations.

Ready to submit your research? Choose BMC and benefit from:

- fast, convenient online submission

- thorough peer review by experienced researchers in your field

- rapid publication on acceptance

- support for research data, including large and complex data types

- gold Open Access which fosters wider collaboration and increased citations

- maximum visibility for your research: over $100 \mathrm{M}$ website views per year

At $\mathrm{BMC}$, research is always in progress.

Learn more biomedcentral.com/submissions 